\title{
Landslide Hazards
}

Associated with

Subduction-Zone Earthquakes

Randall W. Jibson

U.S. Geological Survey

Golden, Colorado 


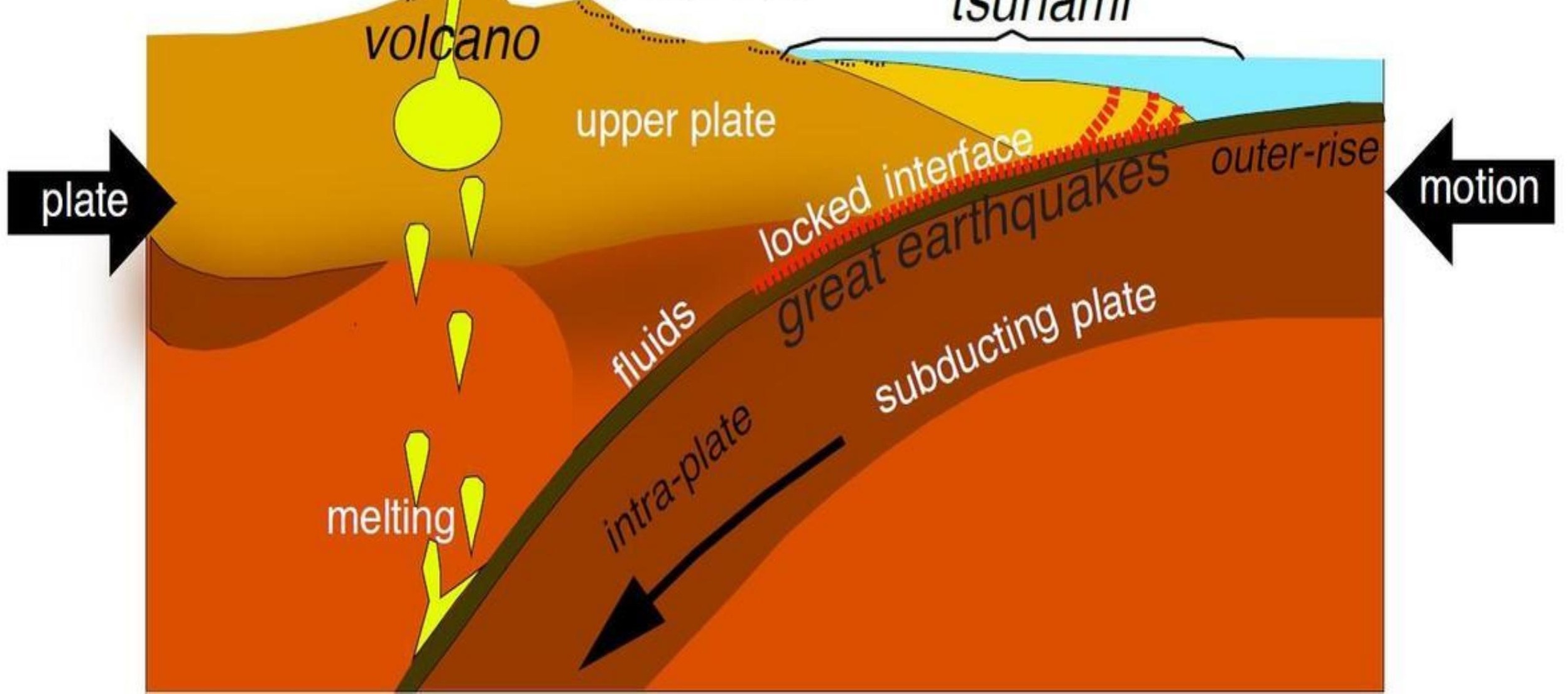




\section{Seismic Landslide Analysis}

$>$ Peak ground acceleration (PGA) commonly sole seismic input

$>$ PGA does not adequately characterize earthquake shaking

$>$ Duration and frequency content also important

$>$ Arias intensity $\left(\mathrm{I}_{\mathrm{a}}\right)$

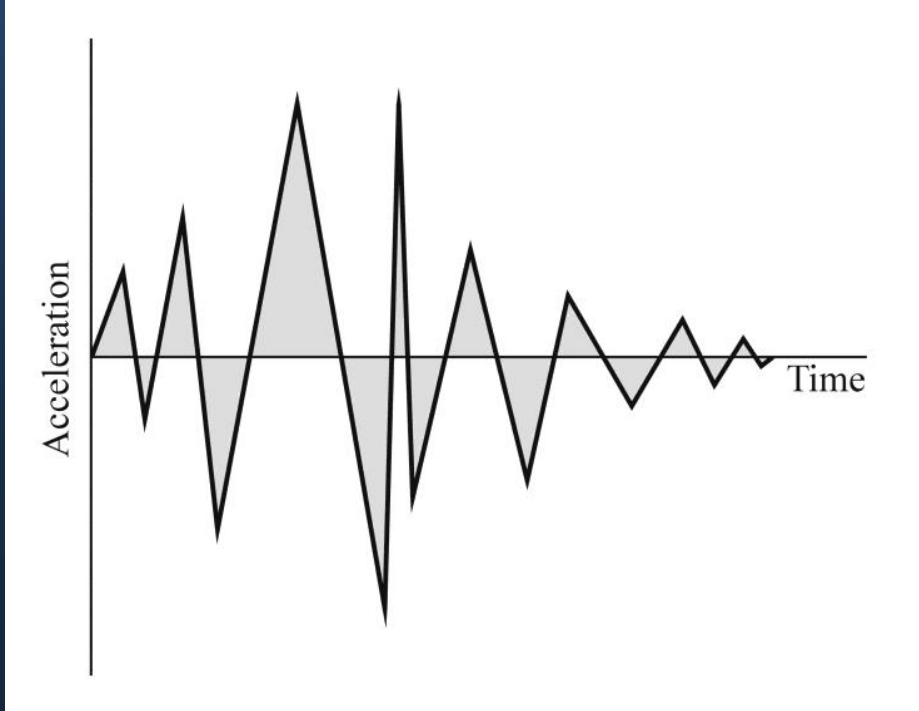


Time Series: Chi-Chi, Taiwan 1999 - CHY080-000
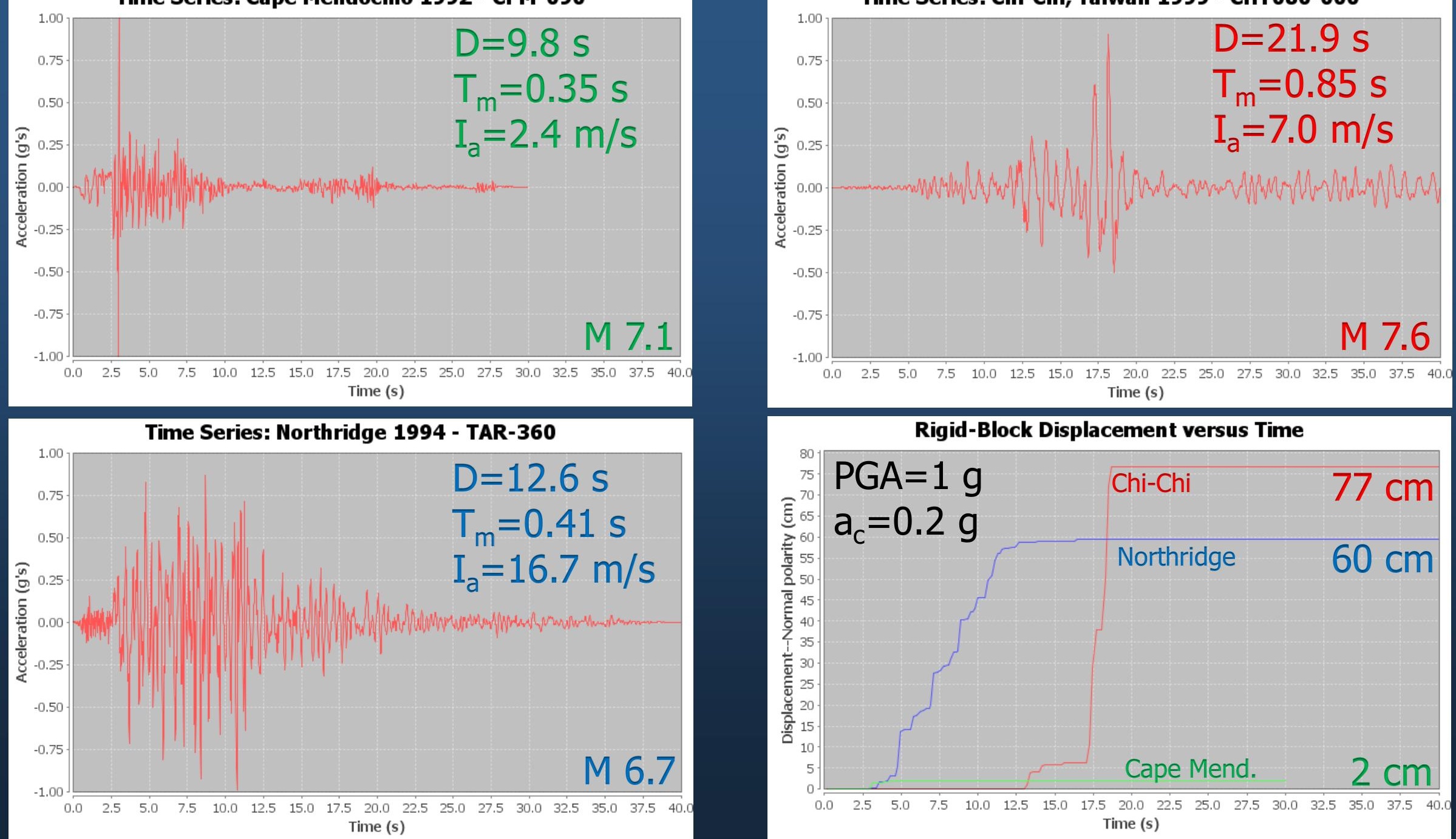


\section{Compare Earthquake Types}

\section{Shallow crustal earthquake}

Frequency $(\mathrm{Hz}) \quad 1-10$

Period (s) $\quad 0.1-1$

Duration (s) $\quad 5-30$ 


\section{Compare Earthquake Types}

Shallow crustal earthquake
Deep subductionzone earthquake

Frequency $(\mathrm{Hz})$

$$
\text { 1-10 }
$$

0.1-1

Period (s)

0.1-1

$1-10$

Duration (s)

5-30

30-120+ 


\section{Northridge earthquake M 6.7}

Rich in high-frequency shaking Shallow, disrupted landslides

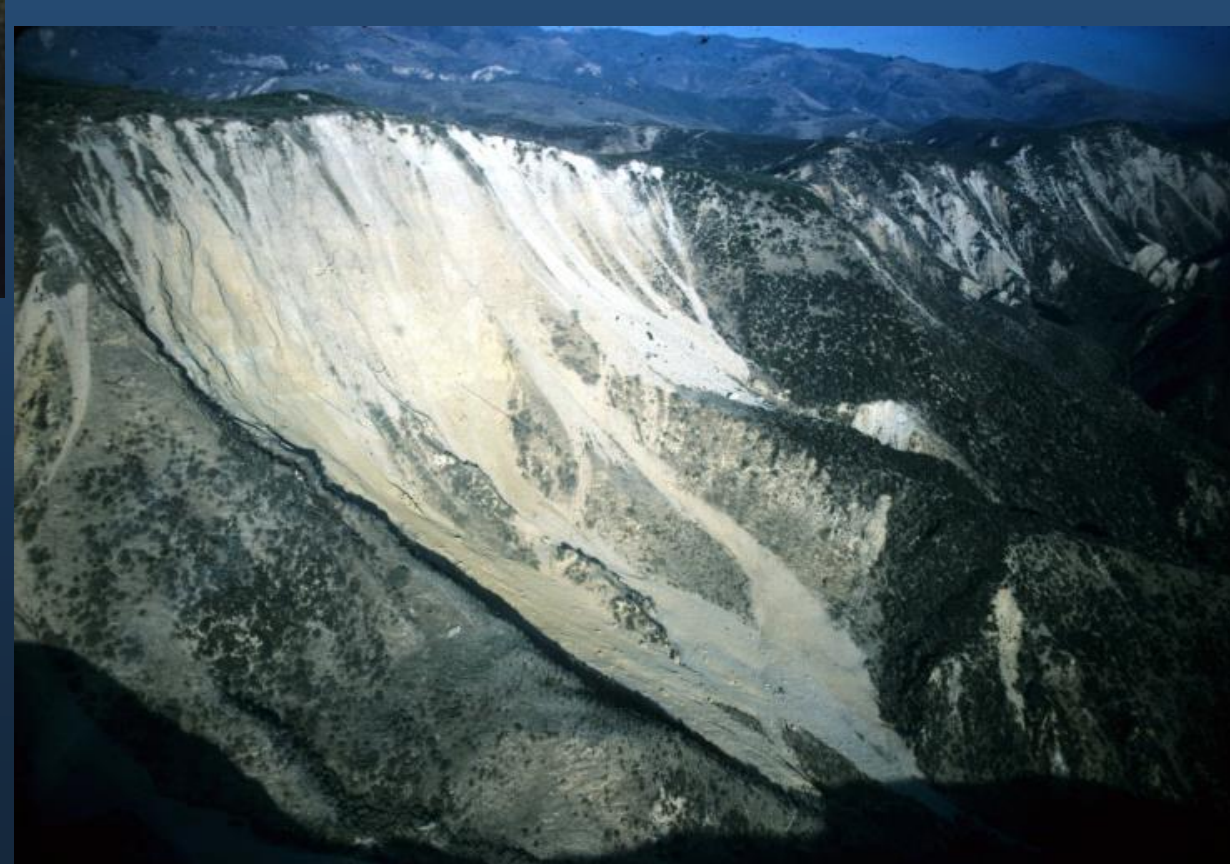




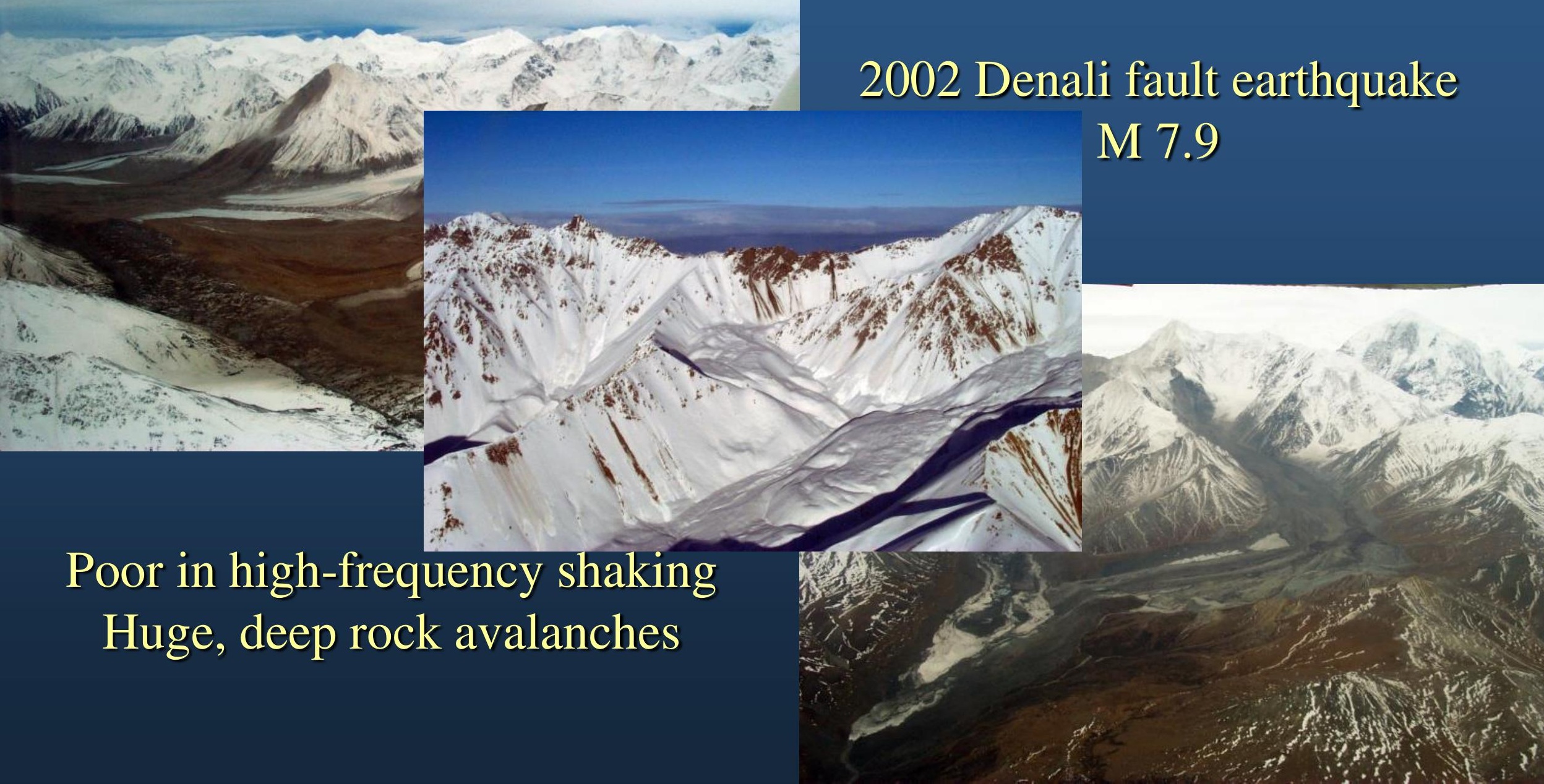




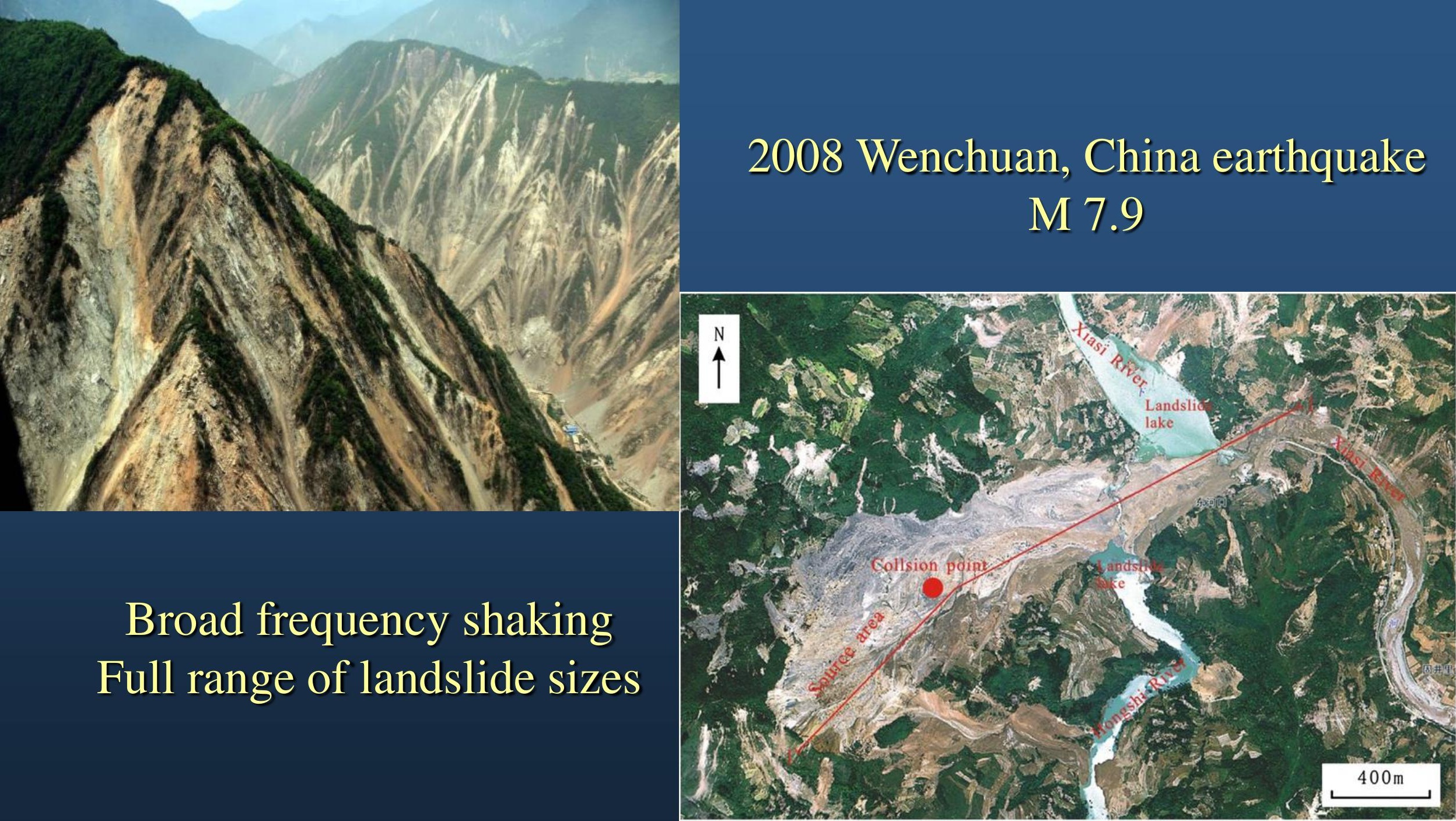




\section{Seismic Incoherence}

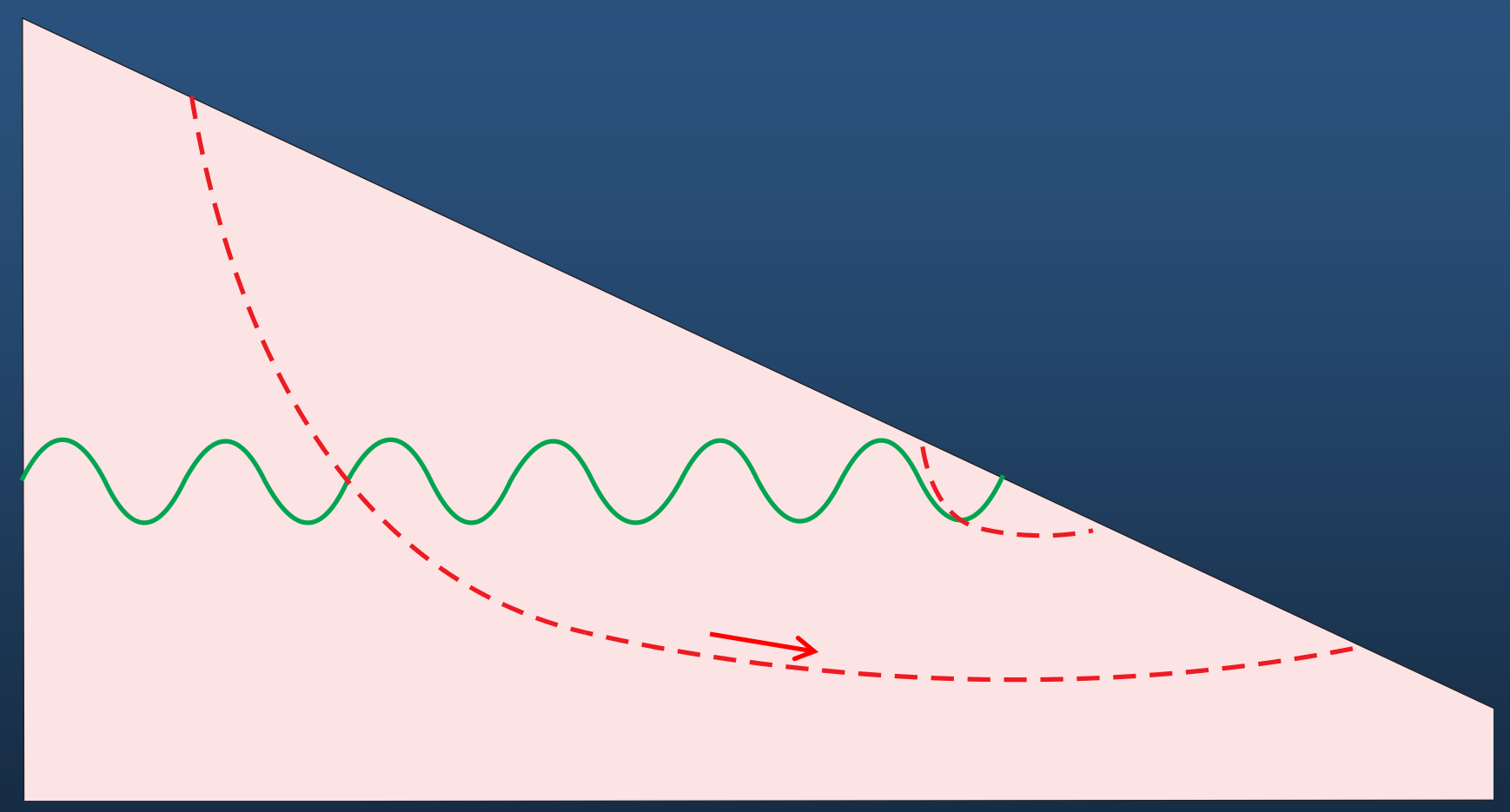




\section{Seismic Coherence}

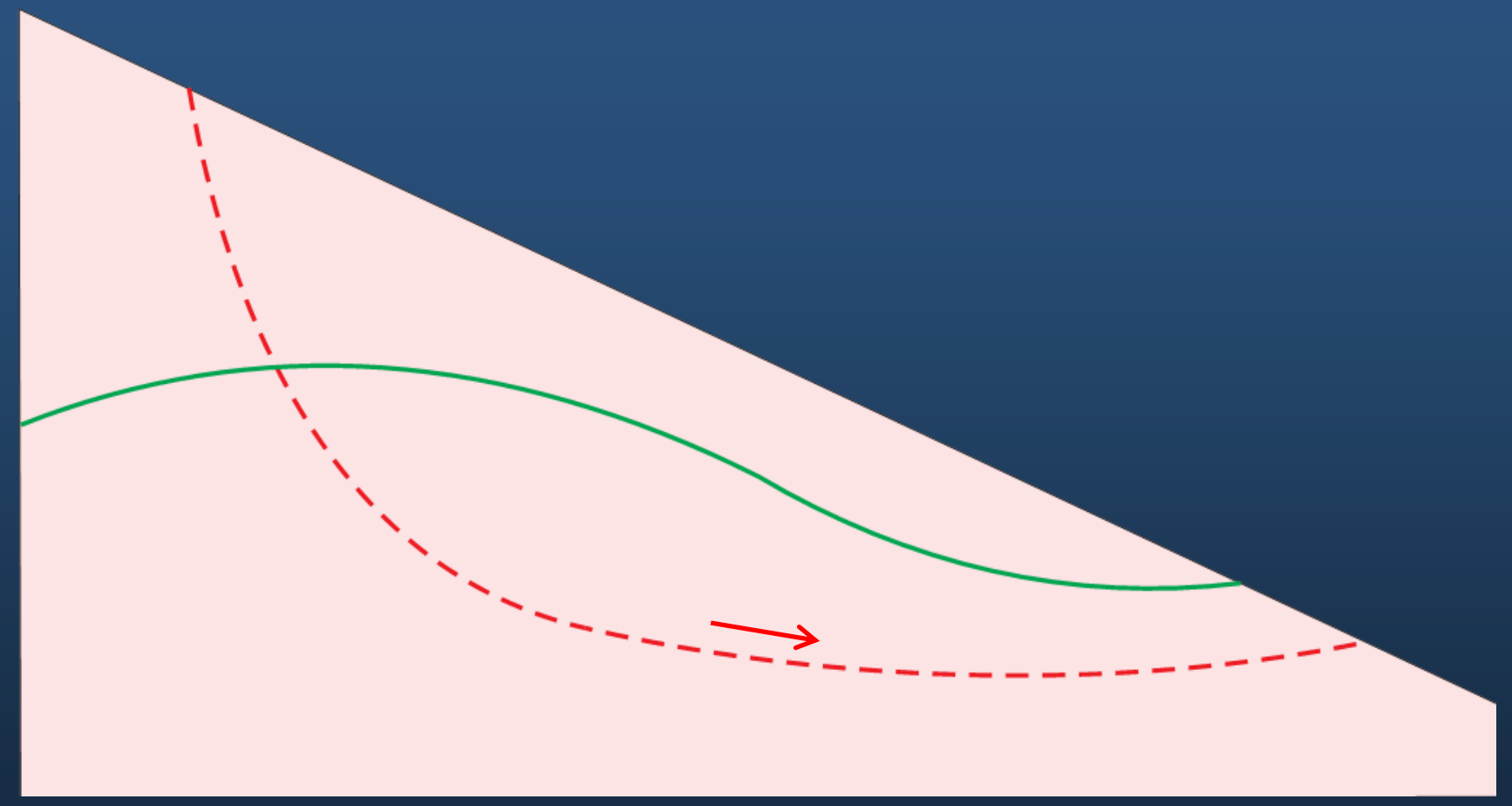




\section{Alaska Earthquake (M 9.2)}

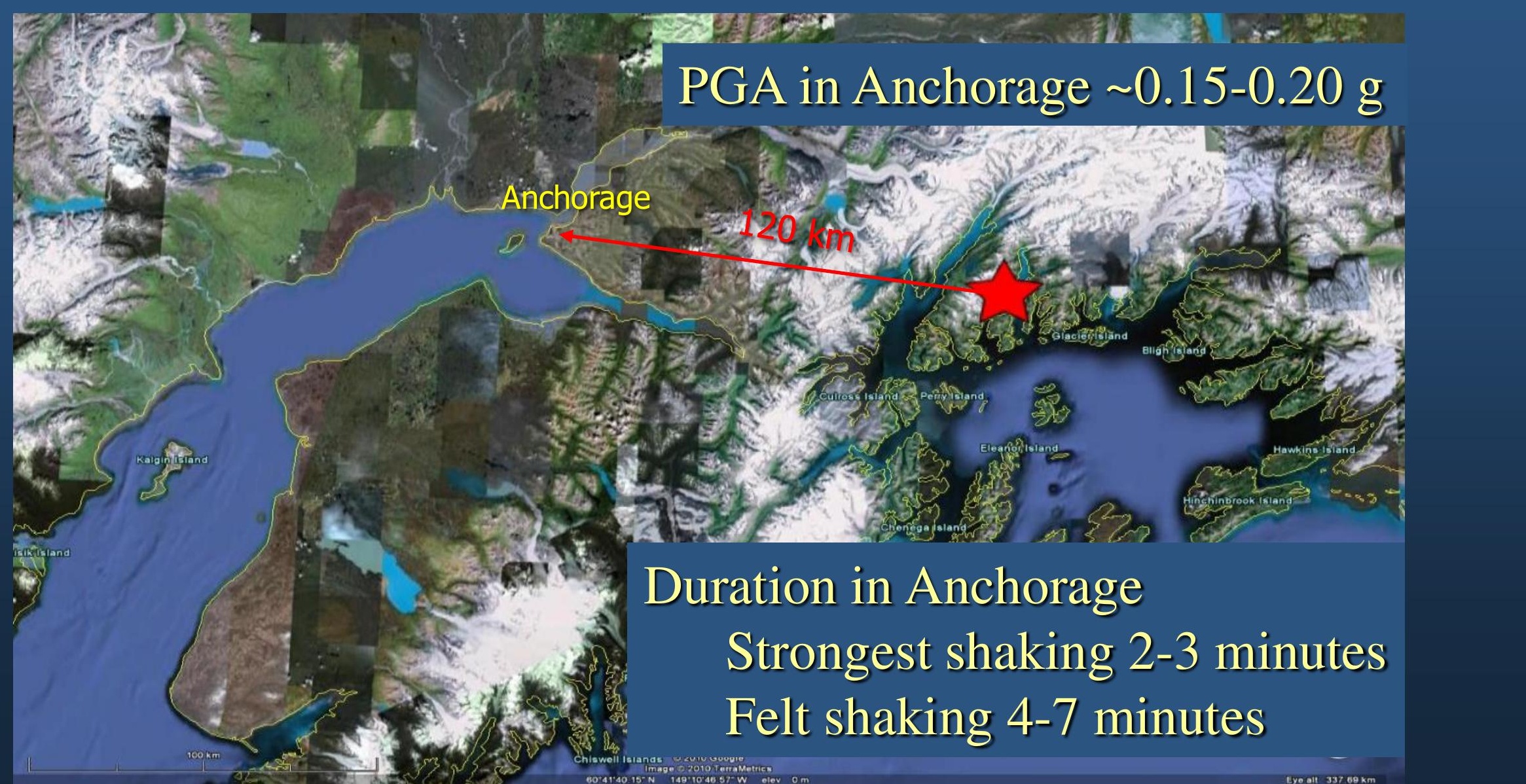




\section{Alaska Earthquake (M 9.2)}

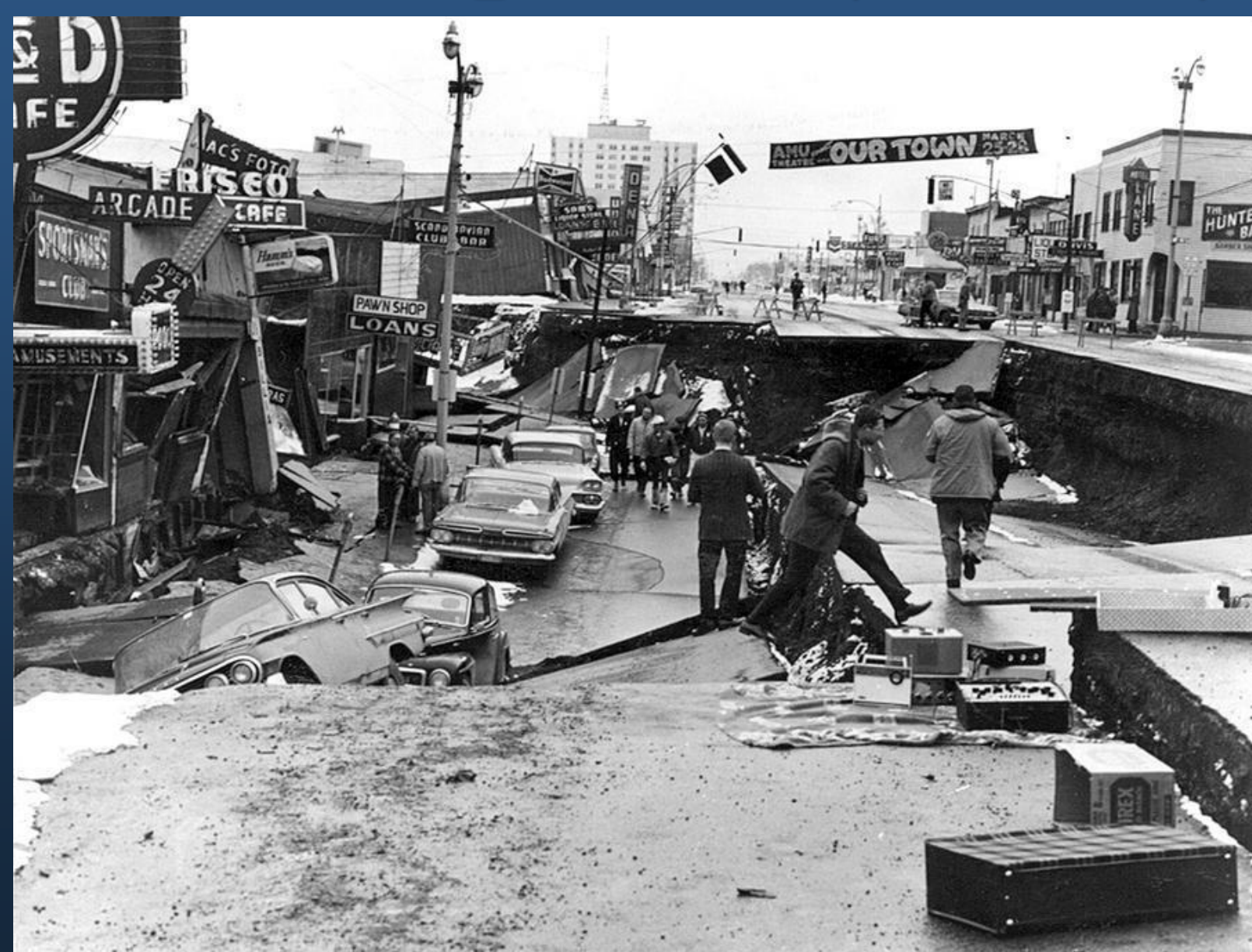

$4^{\text {th }}$ Avenue landslide 


\section{Alaska Earthquake (M 9.2)}

L Street landslide
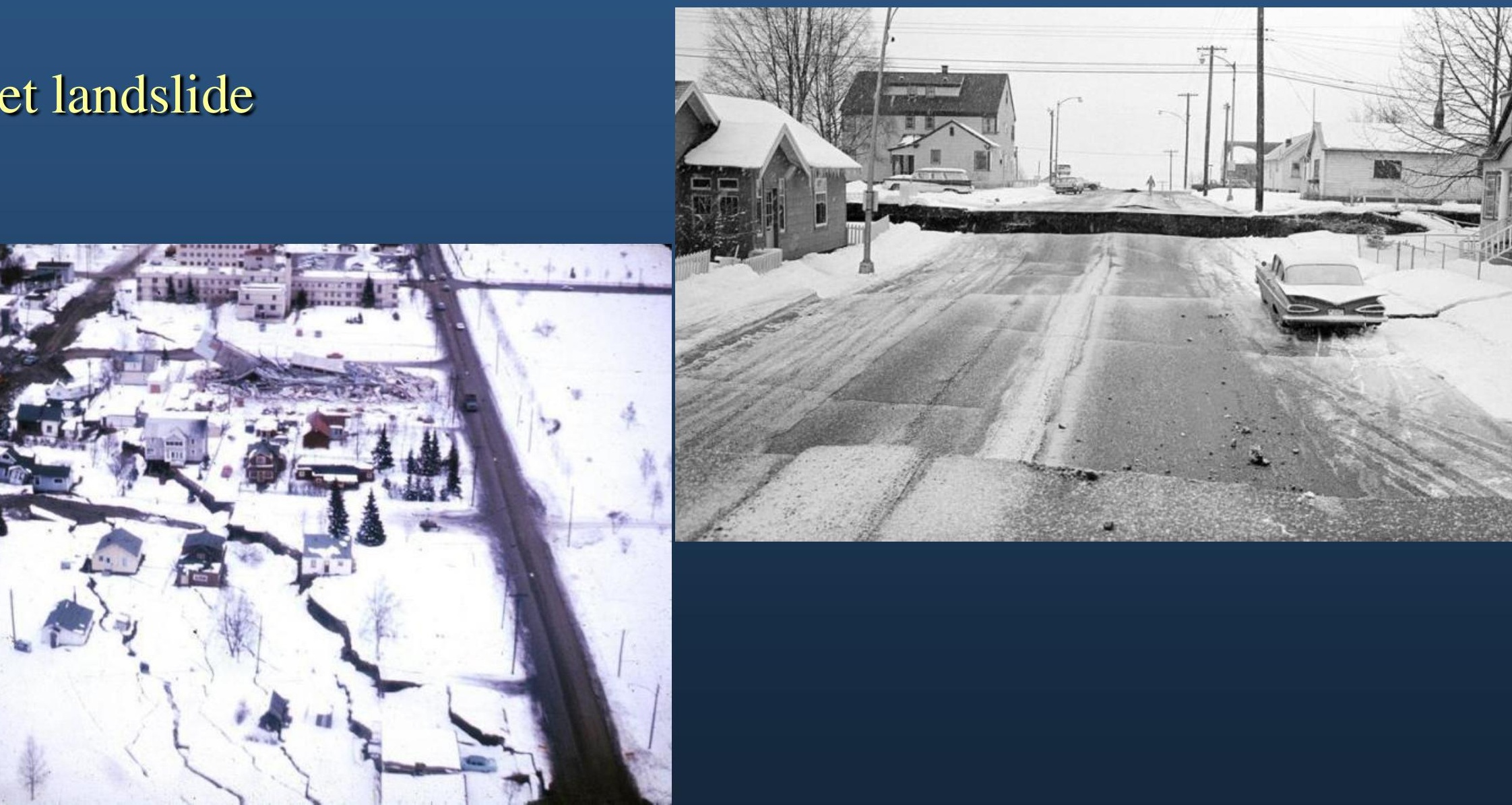


\section{Alaska Earthquake (M 9.2)}

L Street landslide
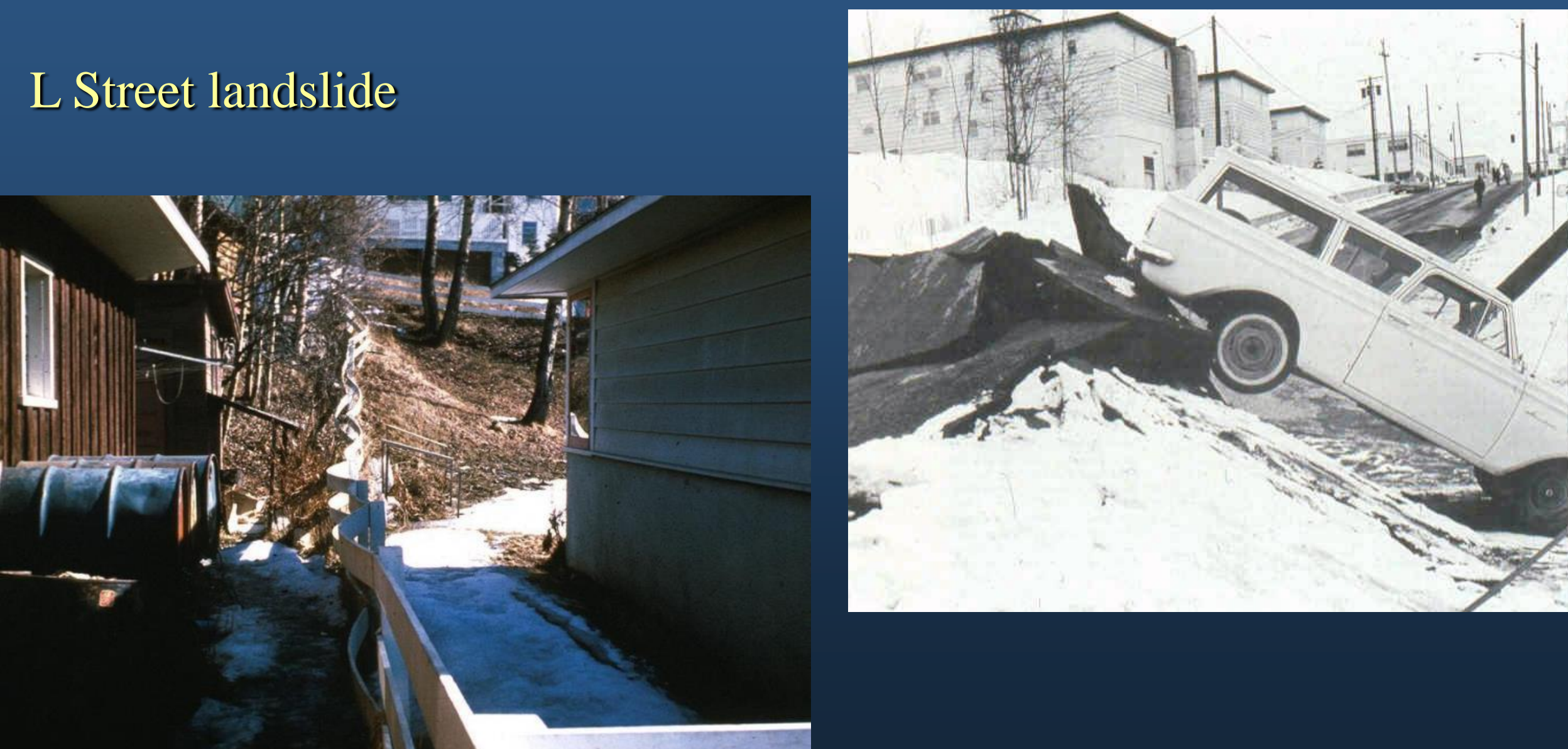


\section{Alaska Earthquake (M 9.2)}

Turnagain Heights landslide

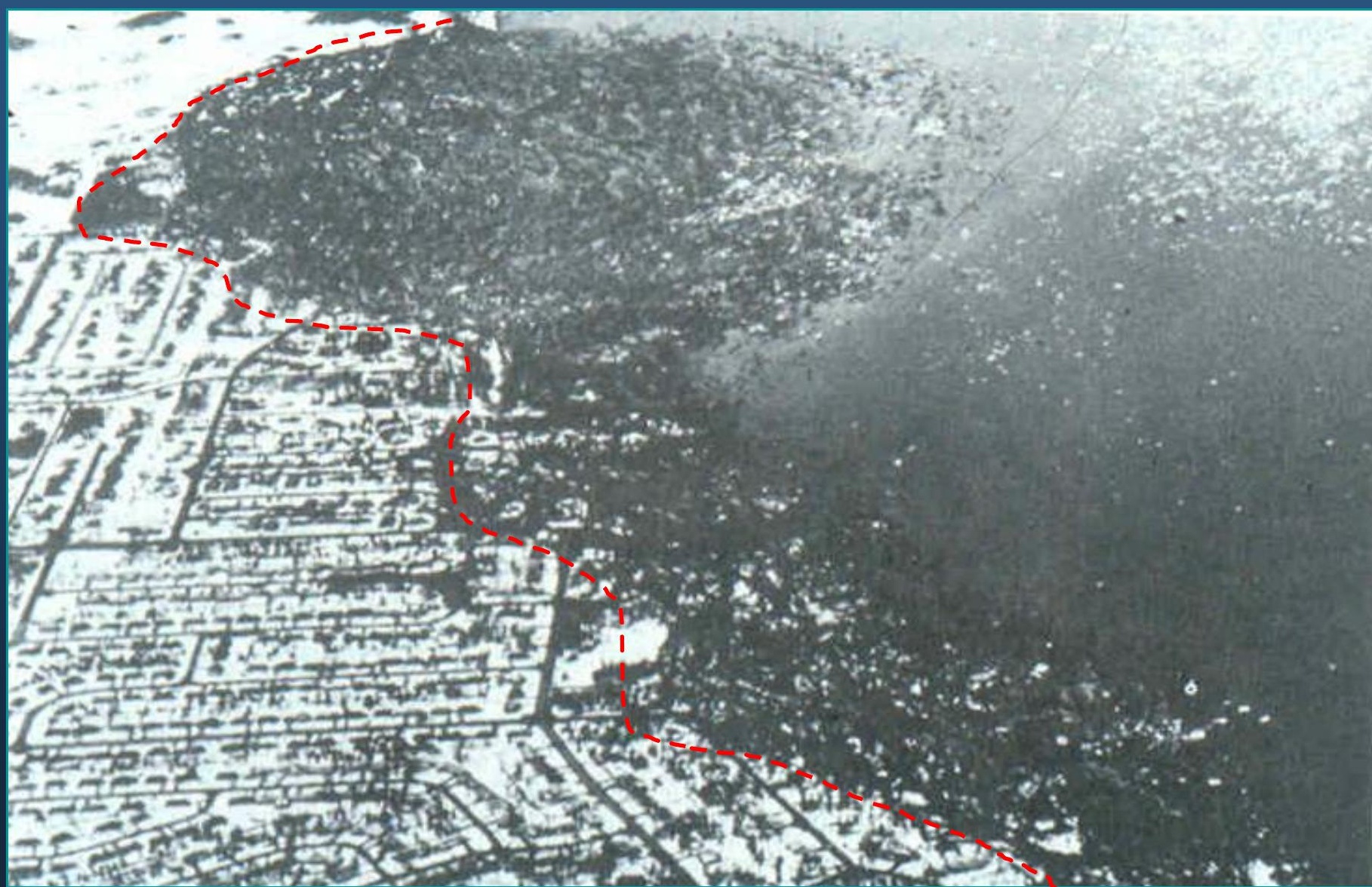




\section{Alaska Earthquake (M 9.2)}

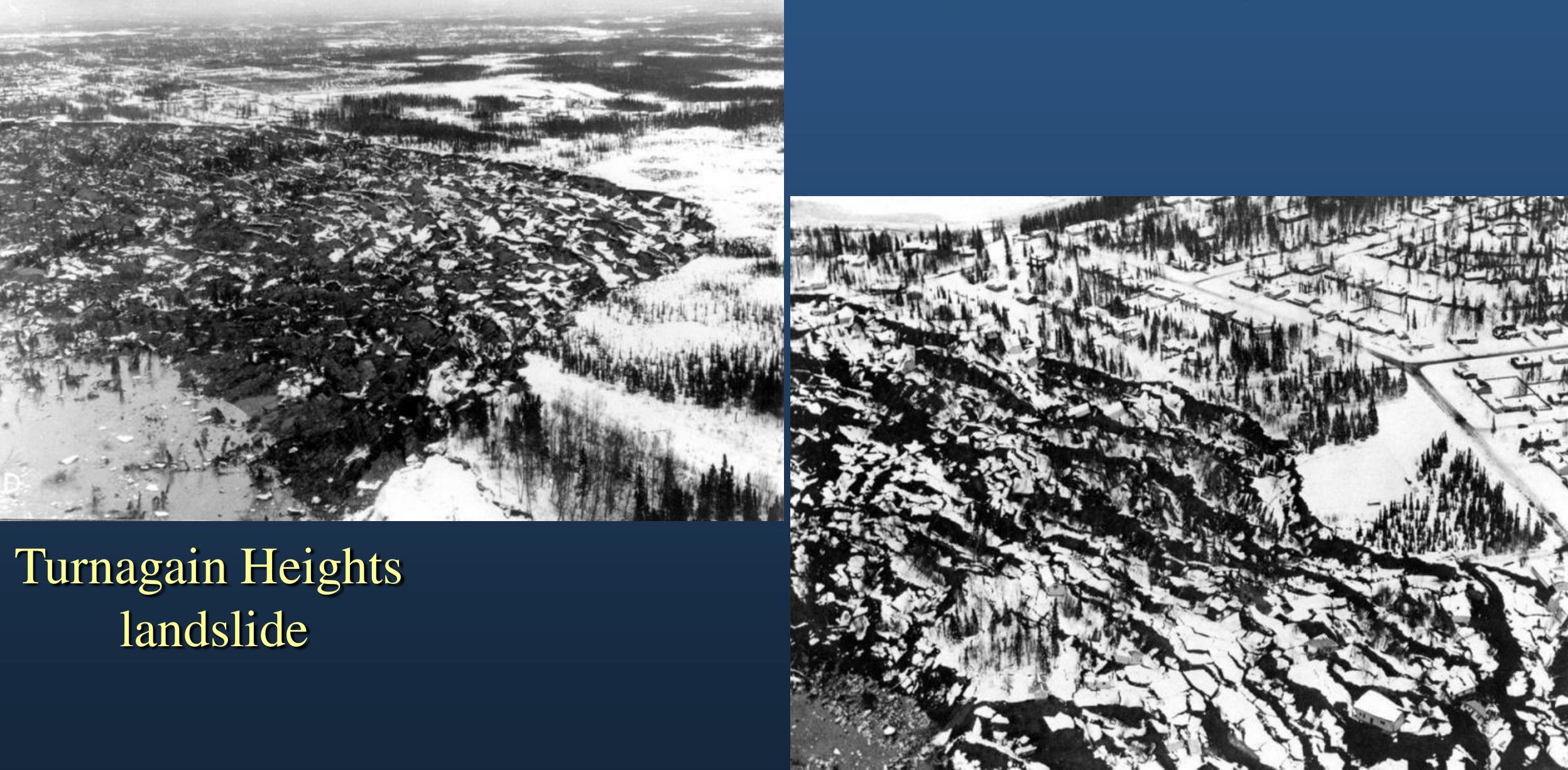




\section{Alaska Earthquake (M 9.2)}

Turnagain Heights landslide

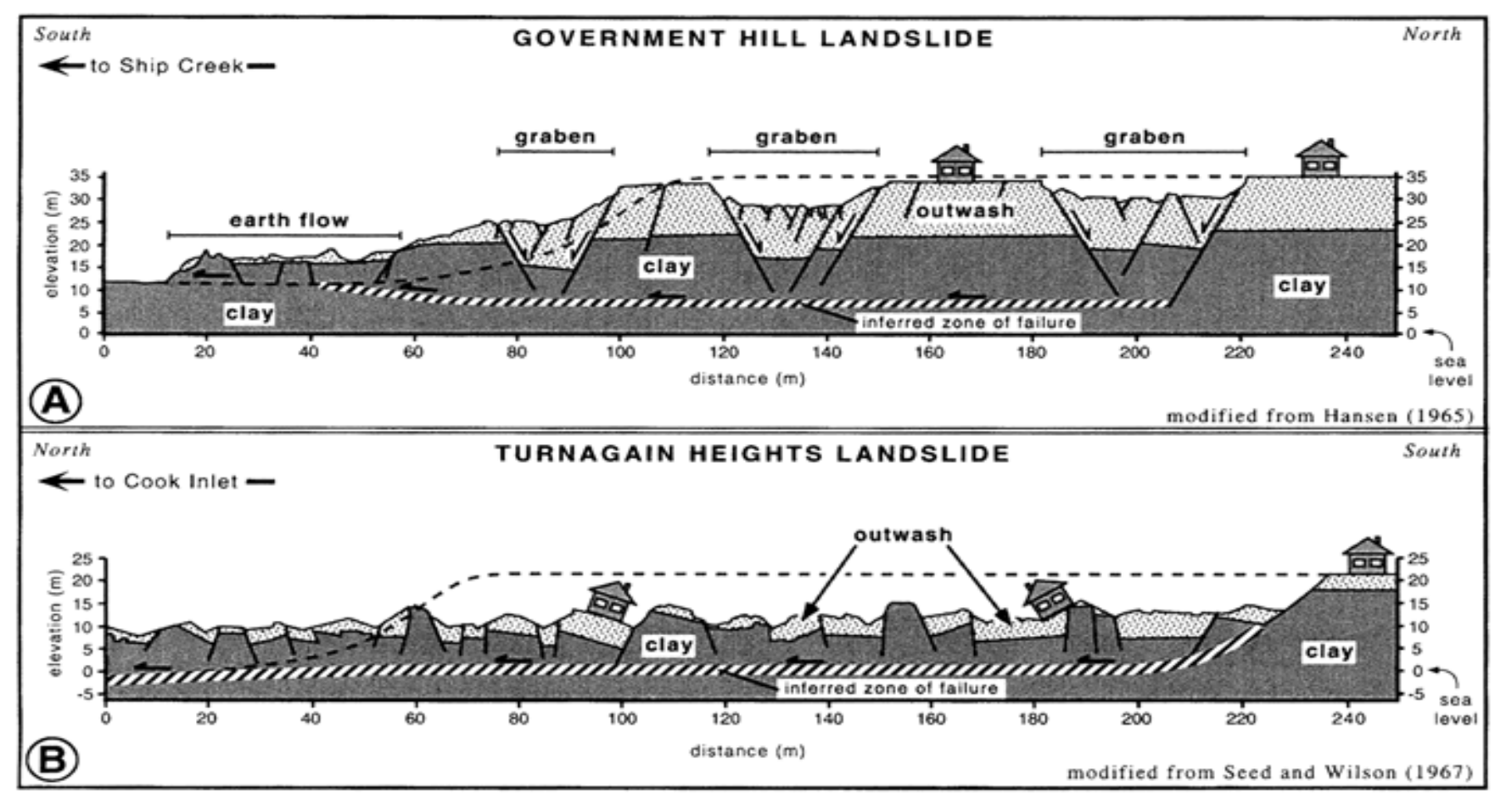




\section{Alaska Earthquake (M 9.2)}

Seward

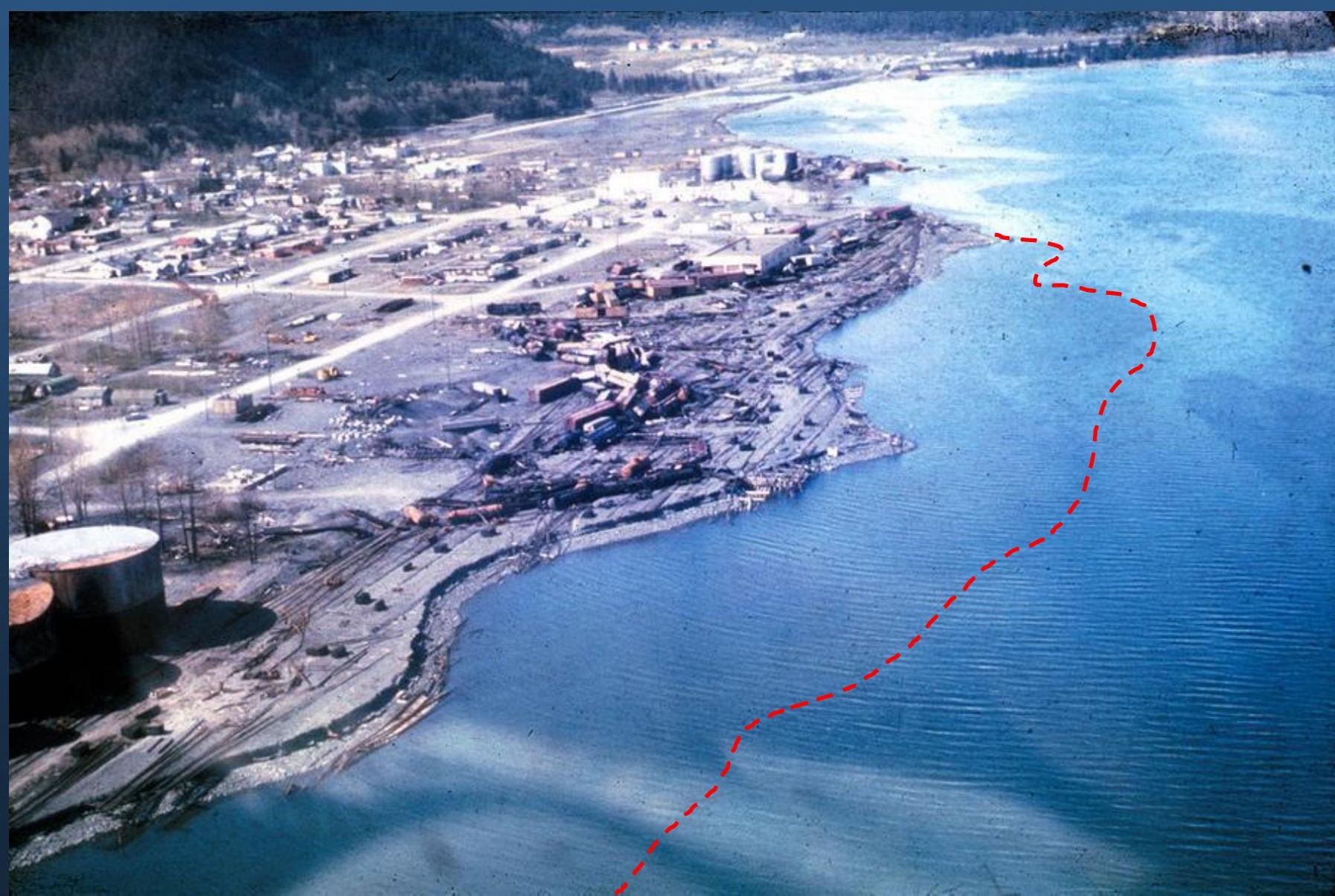




\section{Alaska Earthquake (M 9.2)}

Seward

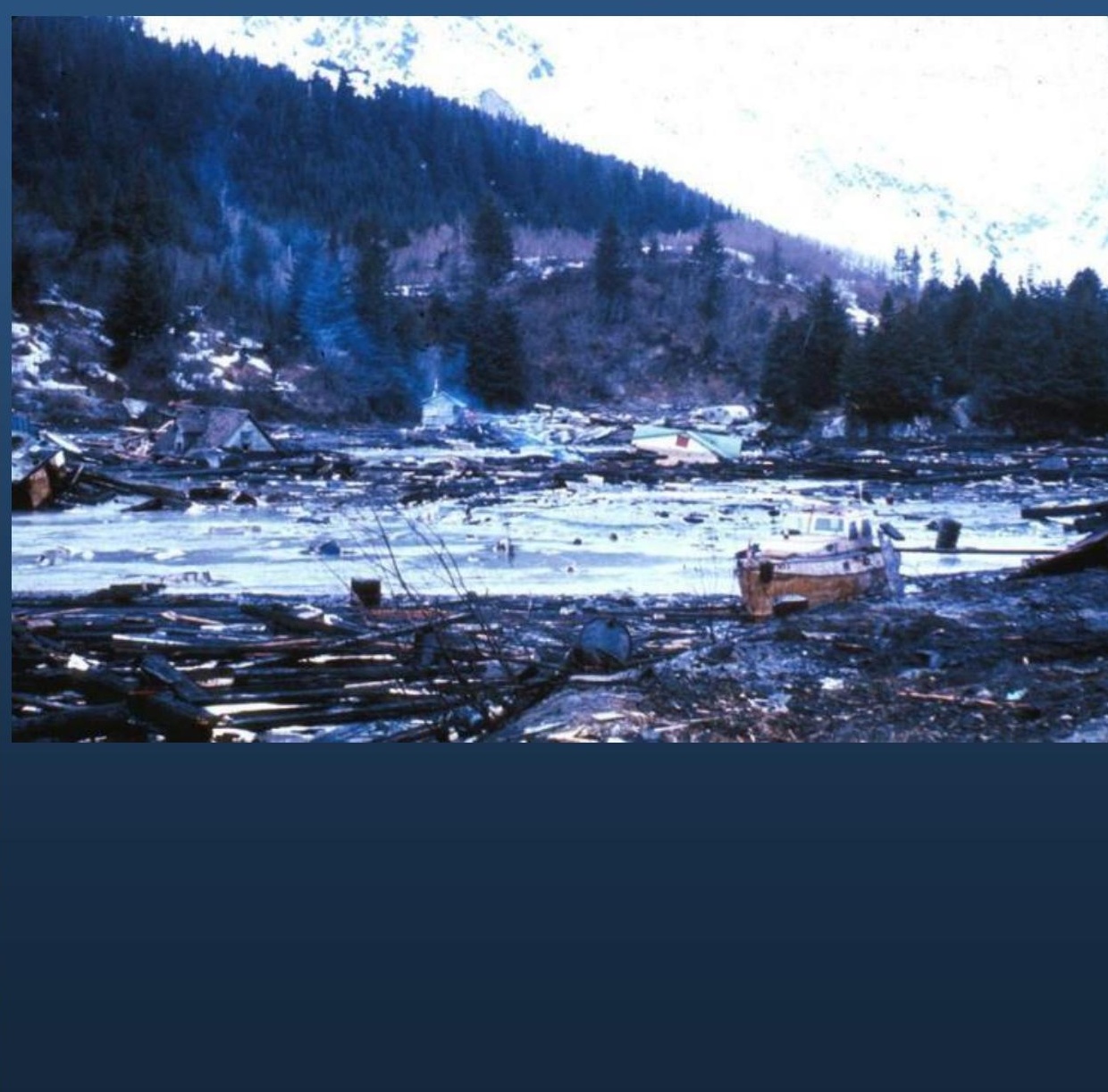

\section{$x^{2}+e^{2}$}
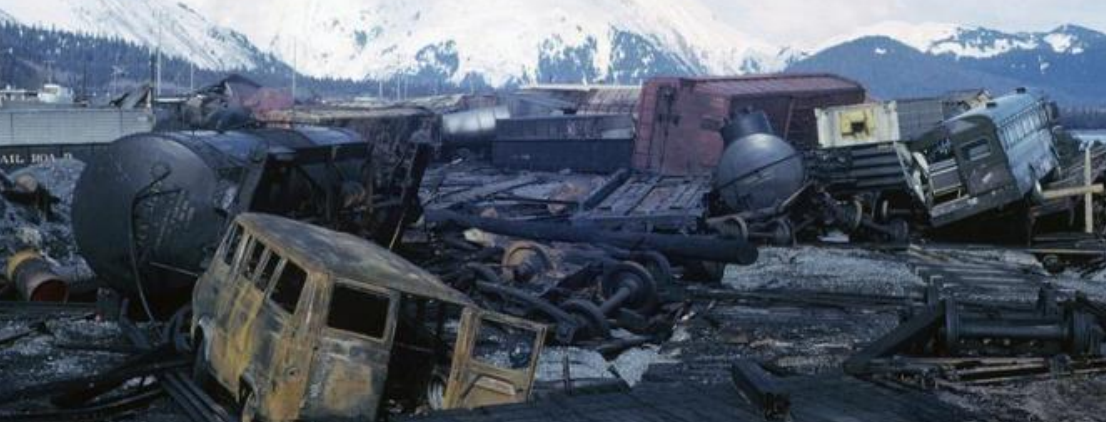

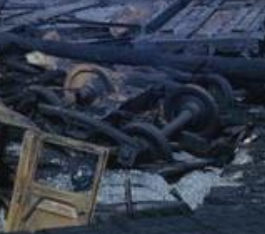

\section{$-$}
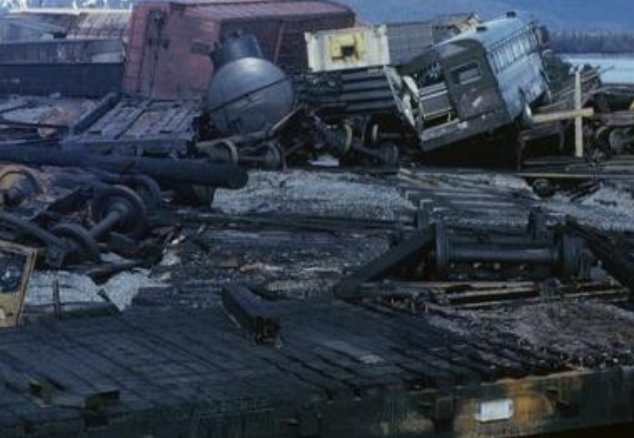

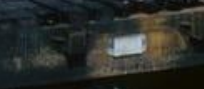

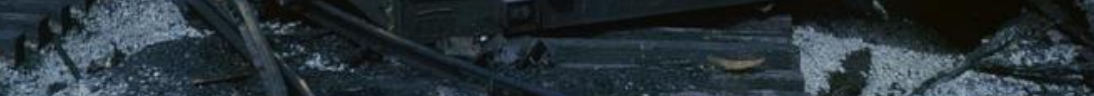
$x=3=1$ 


\section{Alaska Earthquake (M 9.2)}

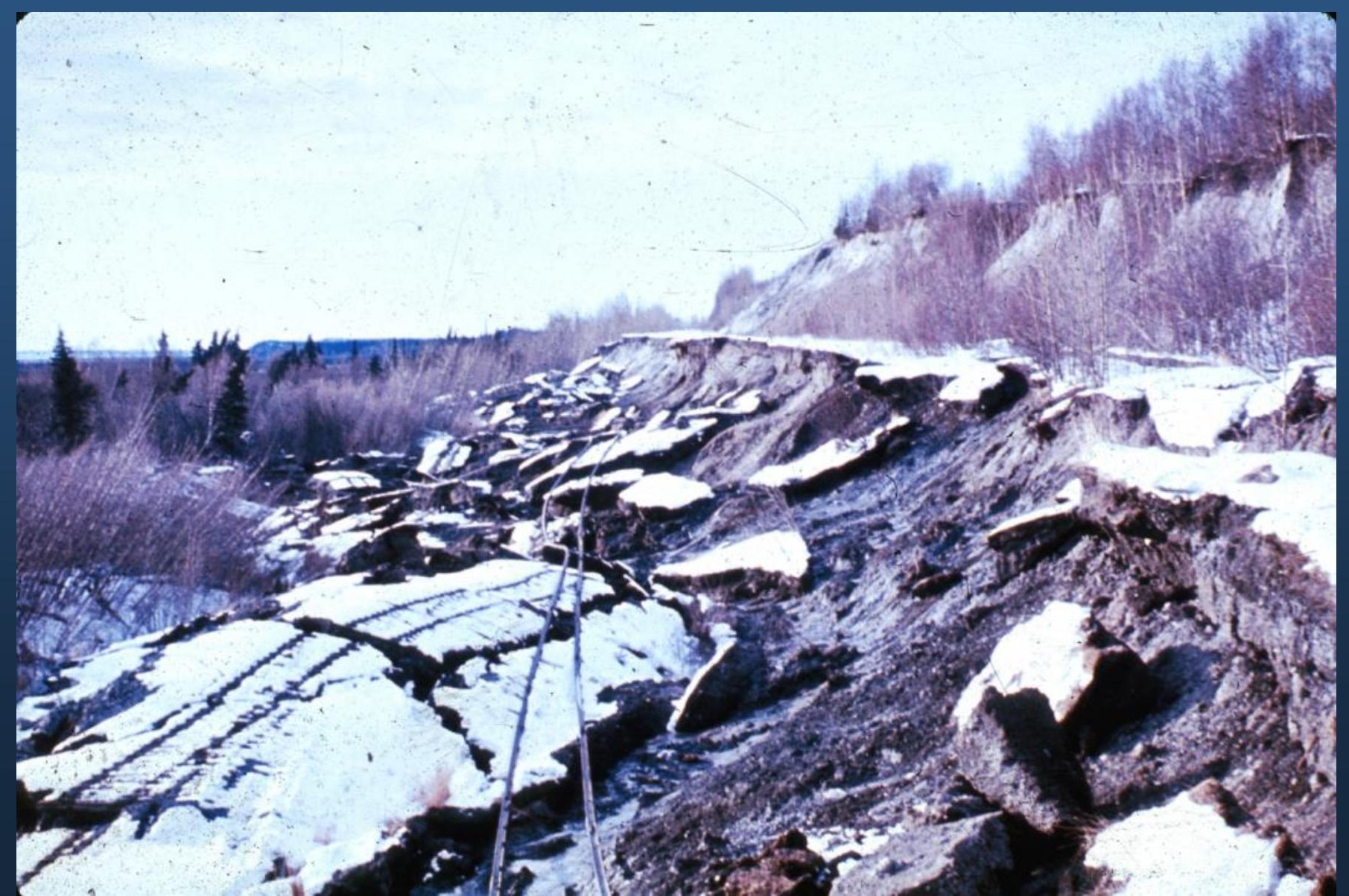




\section{Chile Earthquake (M 9.5)}

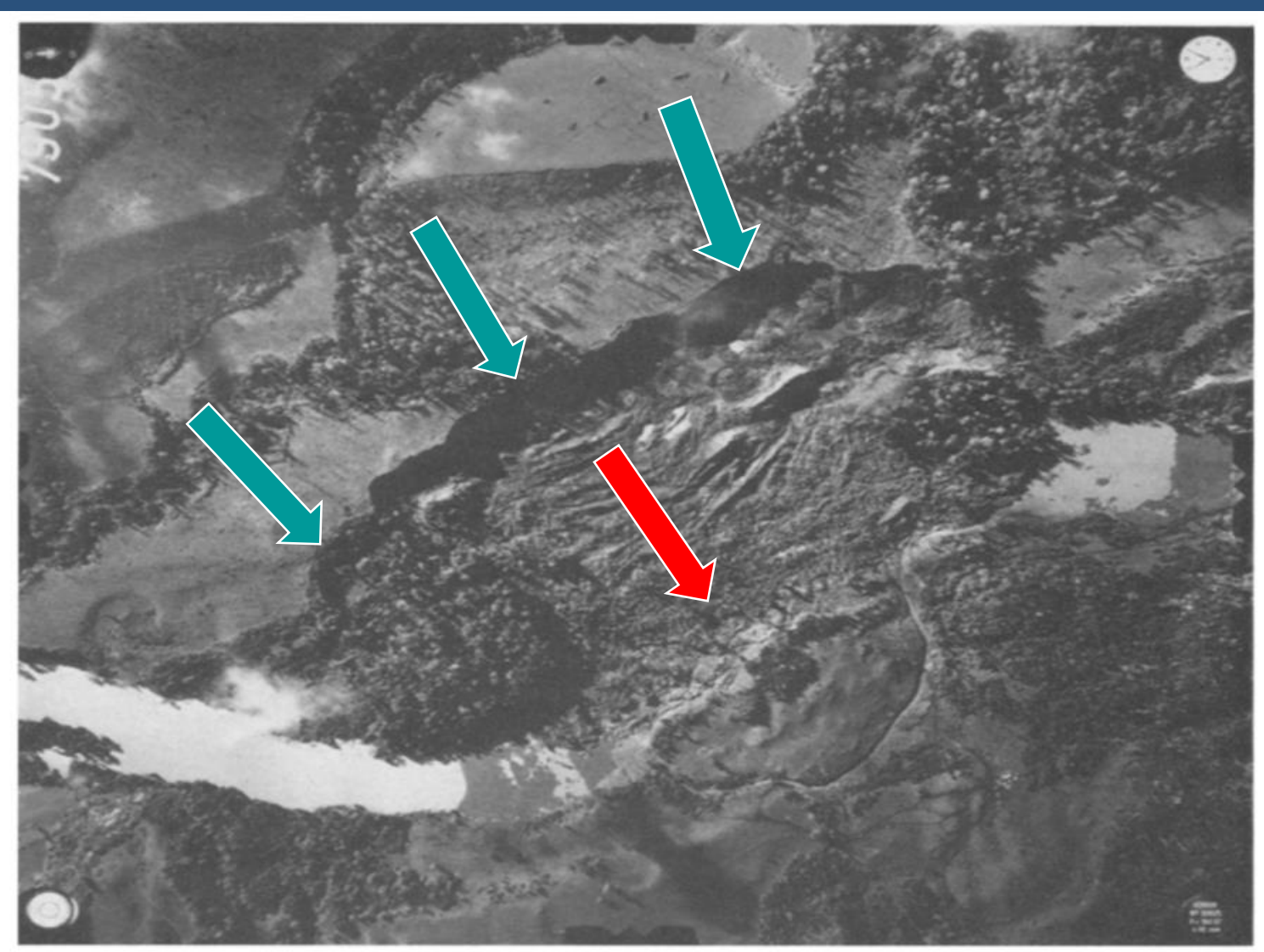

Area: $1.26 \mathrm{~km}^{2}$

Volume: 30 million $\mathrm{m}^{3}$

Runout: 300 m

Material: saturated

sand, silt, ash 


\section{Chile Earthquake (M 9.5)}

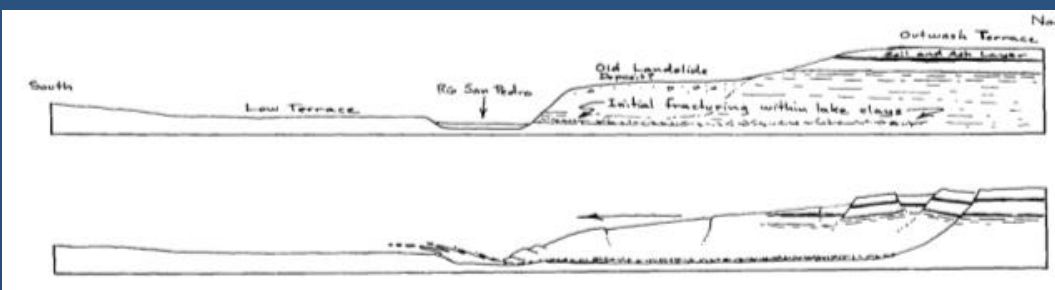

Chile

Alaska
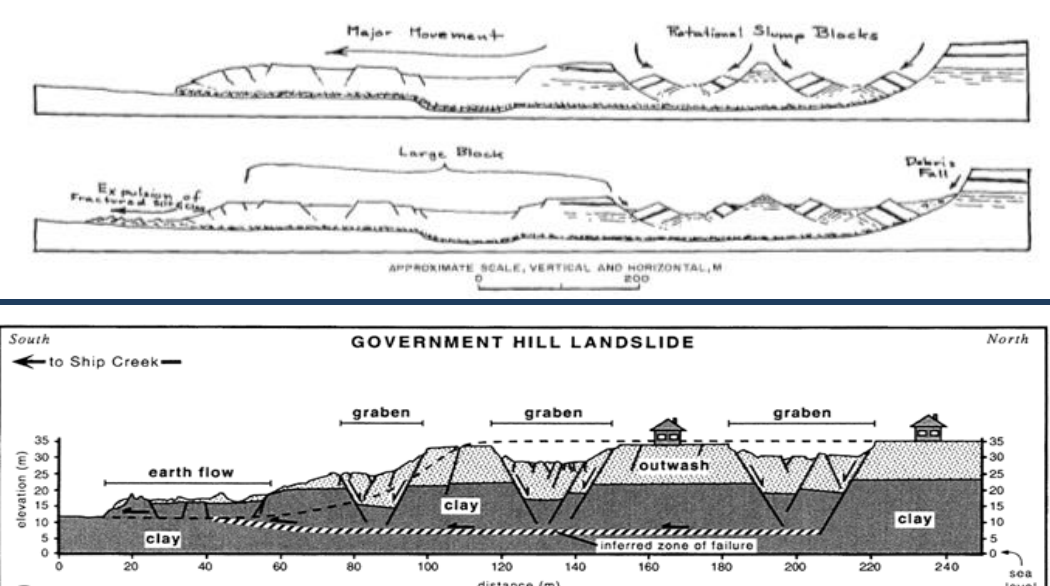

(A)

TURNAGAIN HEIGHTS LANDSLIDE

$\leftarrow$ o cook Inlet -

clay

(B) 


\section{Hazard-Mapping Procedure For Shallow Landslides}

$>$ Collect static data on slope, geology, material shear strength, and groundwater conditions

$>$ Determine PGA of interest from probabilistic seismic hazard analysis (PSHA)

$>$ Conduct Newmark sliding-block analysis

$>$ Assign hazard level based on modeled displacements 


\section{Hazard-Mapping Procedure For Deep Landslides}

$>$ Large, deep landslides require long shaking durations

$>$ PGA is not the principle issue

$>$ Only occur in megathrust events

$>$ Hazard evaluation procedure:

- Identify areas susceptible to deep landslides

- Estimate return periods for megathrust events 



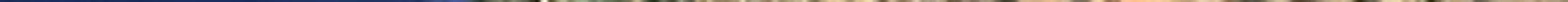

